\title{
Residual Stresses Due to Processing of Composite Tubes $10691-$
}

X.-L. Wang, C. R. Hubbard, S. Spooner, B. Taljat, and J. R. Keiser

Oak Ridge National Laboratory, Oak Ridge, TN 37831-6064

MAY 1,1998

\begin{abstract}
$\mathrm{X}$-ray and neutron diffraction were used to characterize residual stresses in composite tubing of a corrosion-resistant clad alloy on carbon steel. A useful X-ray method, based on the measurement of the $f c c\left(\begin{array}{lll}3 & 1 & 1\end{array}\right)$ reflection using $\mathrm{Cr} \mathrm{K}_{\beta}$ radiation, was developed which allowed precise determination of surface residual stresses in the textured clad layer. Neutron diffraction measurements were carried out in both the carbon steel core and the clad layer, using the $b c c(211)$ and $f c c$ (311) reflections, respectively. The neutron diffraction results are consistent with surface residual stresses determined with $\mathrm{X}$-ray diffraction. However, the through-thickness stress profiles established by $\mathrm{X}$-ray and neutron diffraction do not agree with elastic calculations based on the thermal expansion mismatch between the carbon steel and clad alloy. The differences between the calculation and experimental results are discussed.
\end{abstract}

OSTI

\section{INTRODUCTION}

Co-extruded tubing of type 304L stainless steel on carbon steel, commonly referred to as composite tubing, is an essential part of most recovery boilers in kraft pulp mills. While the use of composite tubes has solved most of the corrosion problems experienced by carbon steel tubes, significant cracking has been reported in the stainless steel layer of composite tubes subjected to periods of service [1]. Microstructural and failure studies suggest that stress corrosion cracking and thermal fatigue are the leading causes for the observed cracking [2]. In either case, residual stresses in the clad layer play an important role in that tensile residual stresses could initiate cracking and assist the propagation of cracks. If, however, the surface is under a compressive residual stress throughout the operating cycle, then stress corrosion cracking is considered unlikely.

To help identify the principal mechanism of cracking experienced by composite tubes, $\mathrm{X}$-ray and neutron diffraction have been used to investigate residual stresses in composite tubes prior to and after use [2-4]. This paper reports the measurement results in as-manufactured composite tubing. The purpose of this study was to provide the base-line residual stress values for use in a finite element model, which is being developed for modeling the thermal-mechanical behavior of recovery boilers during operation, and to explore the experimental difficulties so that an appropriate experimental method and measurement procedure could be developed.

\section{SPECIMEN PREPARATION}

The manufacturing of composite tubing begins with preparing and mating two billets of material, an inner carbon steel and an outer stainless or alloy steel. The combined billet is extruded through a die at high temperature to form a continuous tube, followed by cold reduction to the desirable size. A final annealing or normalizing heat treatment is applied, although the heat treatment temperature and hold time adopted by each manufacturer are

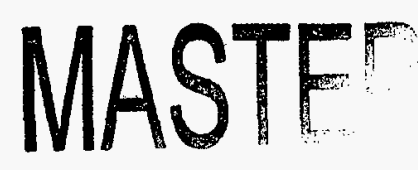

DSTRBBUTON OF THIS DOCUMENT is WMMMIIET

"The submitted manuscript has been authored by a contractor of the U.S. government under contract No. DE-AC05-96OR22464. Accordingly, the U.S. Government retains a nonexclusive, royalty-free license to publish or reproduce the published form of this contribution, or allow others to do so, for U.S. Government purposes." 


\section{DISCLAIMER}

This report was prepared as an account of work sponsored by an agency of the United States Government. Neither the United States Government nor any agency thereof, nor any of their employees, make any warranty, express or implied, or assumes any legal liability or responsibility for the accuracy, completeness, or usefulness of any information, apparatus, product, or process disclosed, or represents that its use would not infringe privately owned rights. Reference herein to any specific commercial product, process, or service by trade name, trademark, manufacturer, or otherwise does not necessarily constitute or imply its endorsement, recommendation, or favoring by the United States Government or any agency thereof. The views and opinions of authors expressed herein do not necessarily state or reflect those of the United States Government or any agency thereof. 
slightly different. Although not indicated in the specimen inspection certificate, it is a common practice that composite tubes are straightened after the heat treatment. Table I summarizes the characteristics of five composite tube specimens investigated in this study. For the neutron diffraction experiments, a set of stress-free reference specimens (for both the carbon steel and the clad layer) was prepared, following the procedure outlined in Wang et al. [4]. A stress-free reference is not needed for the X-ray experiments, since the bi-axial stress condition holds well for metallic components [5].

Table I. Characteristics of specimens used for neutron and X-ray residual stress measurements.

\begin{tabular}{cccccccc}
\hline \hline Manu- & Nominal & \multicolumn{3}{c}{ Materials } & \multicolumn{3}{c}{ Key Dimensions (mm) } \\
facturer & O. D. (in) & Core & Clad & $\phi$ & $t_{c s}$ & $t_{c l}$ & $l$ \\
\hline A & 2.5 & SA210 & $304 \mathrm{~L}$ & 63.6 & 5.2 & 2.0 & 240 \\
A & 2.5 & SA210 & 825 & 63.8 & 5.3 & 1.9 & 240 \\
A & 3.0 & SA210* & $304 \mathrm{~L}$ & 76.2 & 5.2 & 1.9 & 280 \\
A & 3.0 & SA210 & 825 & 76.0 & 5.1 & 2.0 & 280 \\
B & 2.5 & SA210 & $304 \mathrm{~L}$ & 63.6 & 5.2 & 2.0 & 240 \\
\hline \hline
\end{tabular}

$\phi$, actual O. D.; $t_{c s}$, thickness of carbon steel core; $t_{c l}$, thickness of clad layer; $l$, specimen length.

* Grade Al

\section{X-ray and neutron diffraction experiments}

The X-ray experiments were carried out using a portable instrument (TEC, Inc., Knoxville, Tennessee, USA). Initial measurements with $\mathrm{Cr} \mathrm{K}_{\alpha}$ radiation revealed significant texture for the $(220)$ pole which is normally used for residual stress measurements in $f c c$ materials. As a consequence, the d- $\sin ^{2} \Psi$ plot is oscillatory, as shown in Fig. 1(a). This resulted in large uncertainties ( $\pm 40-50 \mathrm{MPa}$ ) for the measured residual stresses. Further X-ray experiments indicated that the (3 111 ) pole, measurable with the $\mathrm{Cr}_{\mathrm{K}}$ radiation, exhibited much weaker texture and hence its d- $\sin ^{2} \Psi$ relationship was quite linear, as illustrated in Fig. 1(b). By measuring the (3 l l $)$ reflection using $\mathrm{Cr}$ $\mathrm{K}_{\beta}$ radiation, an experimental precision of $\pm 10-20 \mathrm{MPa}$ was achieved and this method was employed for the remaining $X$-ray measurements. Pertinent experimental parameters for both type of measurements are listed in Table II.

Table II. Experimental parameters used in X-ray residual stress measurements.

\begin{tabular}{lcc}
\hline \hline & $\mathrm{Cr} \mathrm{K}_{\alpha}$ & $\mathrm{Cr} \mathrm{K}_{\beta}$ \\
\hline$\lambda(\AA)$ & 2.2897 & 2.08487 \\
$(\mathrm{~h} \mathrm{k} \mathrm{l})$ & $(220)$ & $(311)$ \\
$2 \theta\left(^{\circ}\right)$ & 128.7 & 148.6 \\
Slit size $\left(\mathrm{mm}^{2}\right)$ & $1.5 \times 5$ & $1.5 \times 5$ \\
Oscillation range & $\pm 3^{\circ}$ & $\pm 3^{\circ}$ \\
$(1+\mathrm{v}) / \mathrm{E}^{\left(\mathrm{Pa}^{-1}\right)}$ & $7.2 \times 10^{-12}$ & $6.5 \times 10^{-12}$ \\
\hline \hline
\end{tabular}

The neutron diffraction experiments were carried out at the High Flux Isotope Reactor of Oak Ridge National Laboratory using a modified triple-axis spectrometer. 
A ( 1110$)$ reflection from a beryllium crystal was used as the monochromator. The take-off angle for the monochromator was set at $84^{\circ}$ and the incident neutron wavelength was $1.513 \AA$. Neutron diffraction peak profiles were recorded with a position-sensitive detector. For measurements of the radial and hoop strains $\left(\varepsilon_{\pi}\right.$ and $\left.\varepsilon_{\theta \theta}\right)$, the specimen was mounted upright. Slits of dimensions $0.6 \times 30 \mathrm{~mm}^{2}$ were inserted before and after the specimen, which together defined a sampling volume of $10.8 \mathrm{~mm}^{3}$. For measurements of the axial strain $\left(\varepsilon_{\mathrm{zz}}\right)$, the specimen was mounted horizontally. Slits of dimensions $1 \times 4 \mathrm{~mm}^{2}$ and $1 \times 30 \mathrm{~mm}^{2}$ were used in this case, and the sampling volume thus defined was $4 \mathrm{~mm}^{3}$. Residual strains in both the carbon steel core and the clad layer were determined, using the $b c c(211)$ and $f c c(311)$ reflections, respectively. Residual stresses in each specimen were derived from the residual strain data using Hooke's law. The diffraction elastic constants used for calculations were: $E=210 \mathrm{GPa}$ and $v=0.28$ for the (211) reflection of carbon steel, and $E=184 \mathrm{GPa}$ and $v=0.29$ for the (311) reflection of the clad alloy (304L or 825) [4].
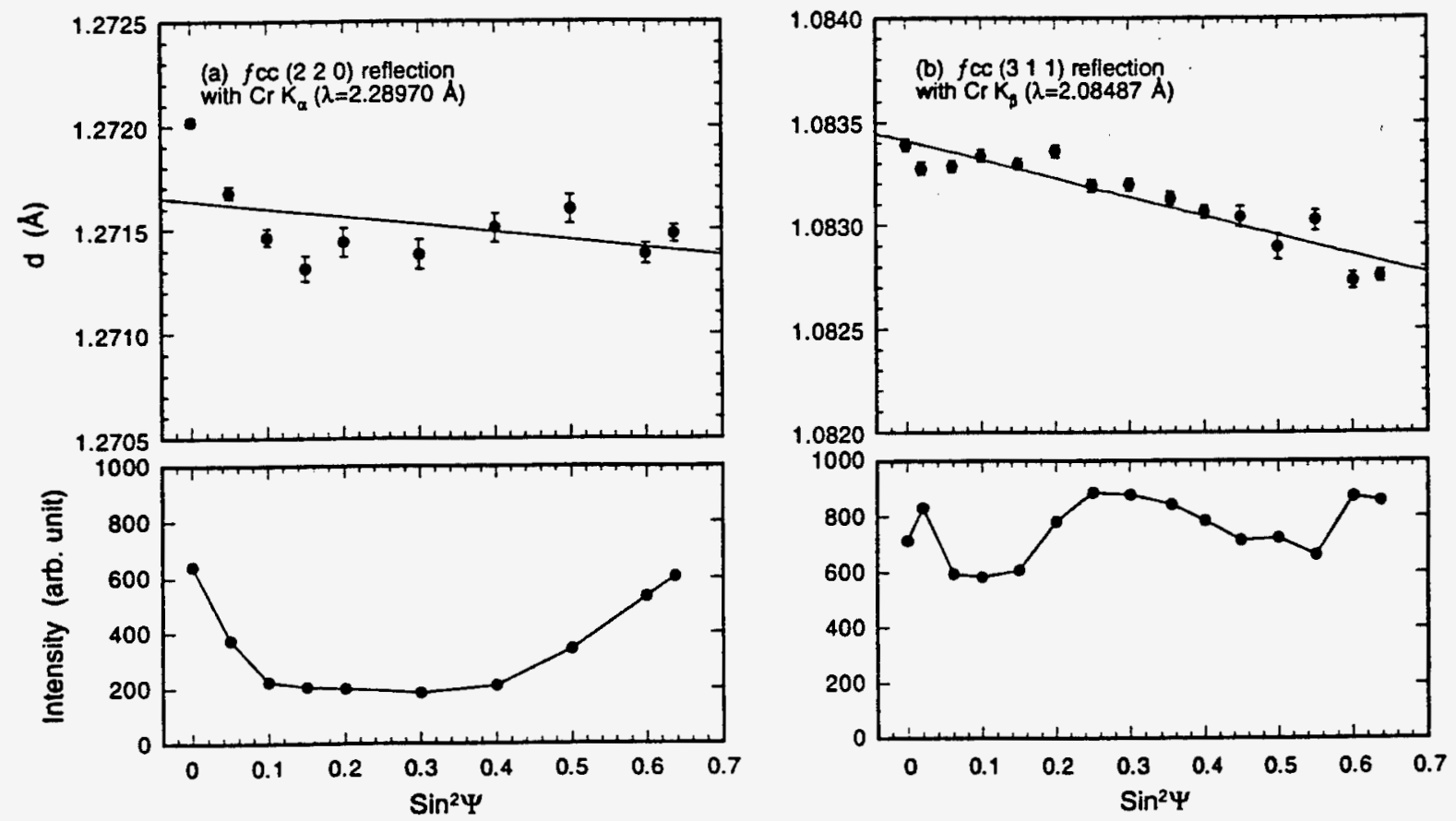

Fig. 1 Representative d- $\sin ^{2} \Psi$ and intensity plots for (a) (2 20 ) and (b) (3 111 ) reflections, measured with $\mathrm{Cr} \mathrm{K}_{\alpha}$ and $\mathrm{Cr} \mathrm{K}_{\beta}$ radiation, respectively. The solid lines in the $\mathrm{d}-\sin ^{2} \Psi$ plot are least-squares fits to the measured $d$.

\section{RESULTS}

At a given depth, residual stresses in tubes from manufacturer A (MA) are nonuniform; they vary along both the circumference and length. This was first revealed in the surface X-ray experiments and later confirmed by through-thickness neutron diffraction measurements. For some of the specimens, a sign change was observed along the circumference. Fig. 2 compares the angular dependence of hoop strains measured with $\mathrm{X}$-ray and neutron diffraction, respectively. The neutron data set, collected at mid depth in the clad layer, exhibits a systematic change as a function of the angular position. The surface X-ray data correlate very well with the neutron data. This correlation establishes 
that the non-uniform residual stresses in MA tubes are not limited to the surface but are characteristic of the entire clad layer. The specimen from manufacturer B (MB) also exhibits a varying residual stress, although the degree of variation is much smaller.

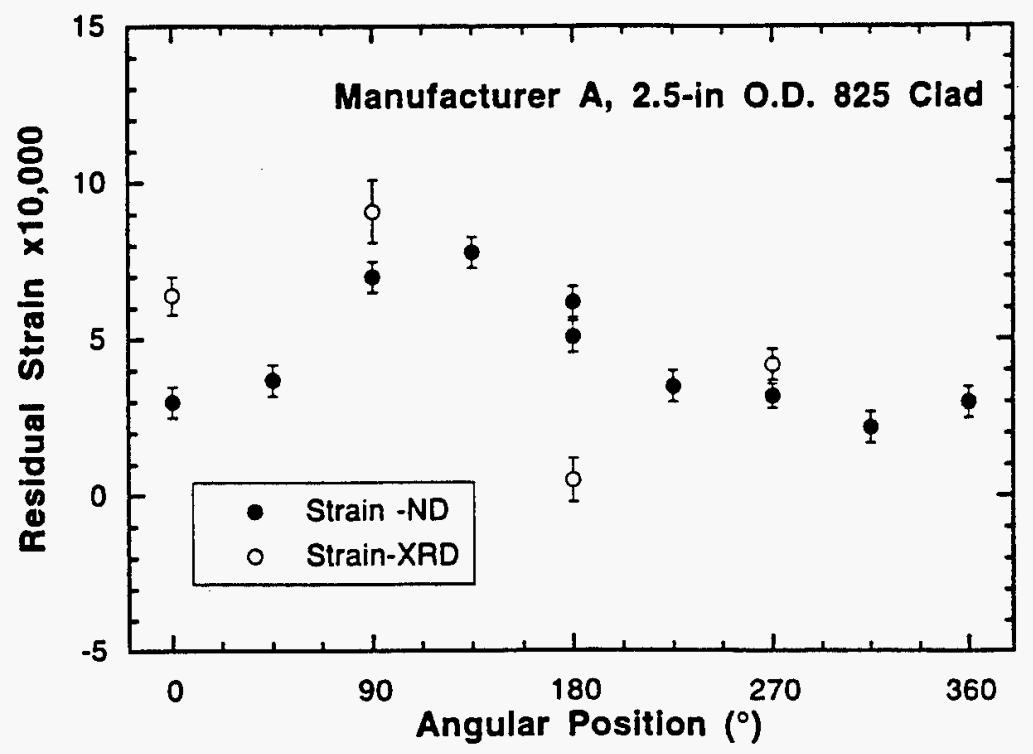

Fig. 2 Angular dependence of hoop residual strains in the clad layer of MA 2.5-in 825. The neutron diffraction measurements were made at mid depth and each data point represents an average over an area of $0.6 \times 0.6 \mathrm{~mm}^{2}$ in the circular plane. The $\mathrm{X}$-ray data were collected at $25 \mu \mathrm{m}$ below the surface (with electro-polishing).

The varying residual stresses at a given depth made it rather difficult to interpret the through-thickness stress profile obtained for each specimen, for data collected at a particular angular position may not be representative. Fortunately, there are two specimens, MA 3-in 825 and MB 2.5-in 304L, whose residual stresses did not show large variations at a given depth. Fig. 3 shows their through-thickness stress profiles determined with neutron and X-ray diffraction. Two common features can be seen. First, the residual stresses in the clad layer are tensile near the interface, decreasing linearly as the outer surface is approached. Second, the axial $\left(\sigma_{z z}\right)$ and hoop $\left(\sigma_{\theta \theta}\right)$ stresses are almost equal in the carbon steel core. Despite these similarities, the stress profiles shown here are not quite the same. For example, the slope of decrease in the clad layer is greater for MB 2.5-in $304 \mathrm{~L}$, whose outer surface is in deep compression. Also, while residual stresses in the carbon steel of MA 2.5 -in 304L vary strongly as a function of the radial position, they are almost constant in MB 3-in 825. The experimentally determined radial stress $\left(\sigma_{\pi}\right)$ is nearly zero for both tubes at all locations, as they should be due to the small wall-thickness of the tube specimens.

\section{DISCUSSION}

In general, residual stresses in composite tubes are generated at each stage of the manufacturing process. However, since the final heat treatment temperature is rather high $\left(920-950^{\circ} \mathrm{C}\right)$, residual stresses generated prior to the heat treatment are expected to be fully eliminated [4]. Upon cooling from the heat treatment temperature, residual stresses re-develop due to the thermal expansion mismatch between the carbon steel core and the 
clad layer. Additional residual stresses are generated by subsequent finishing processes (e.g., straightening).

In the absence of yielding, residual stresses induced by thermal expansion mismatch can be calculated analytically [6]. As shown in Fig. 3, the calculated residual stresses have a weak radial dependence. For specimens under study, the clad layer is in tension and the carbon steel core is in compression, due to the higher coefficient of thermal expansion of the clad layer. Subsequent finite element analyses confirmed that these qualitative features do not change even if yielding occurs during cooling.
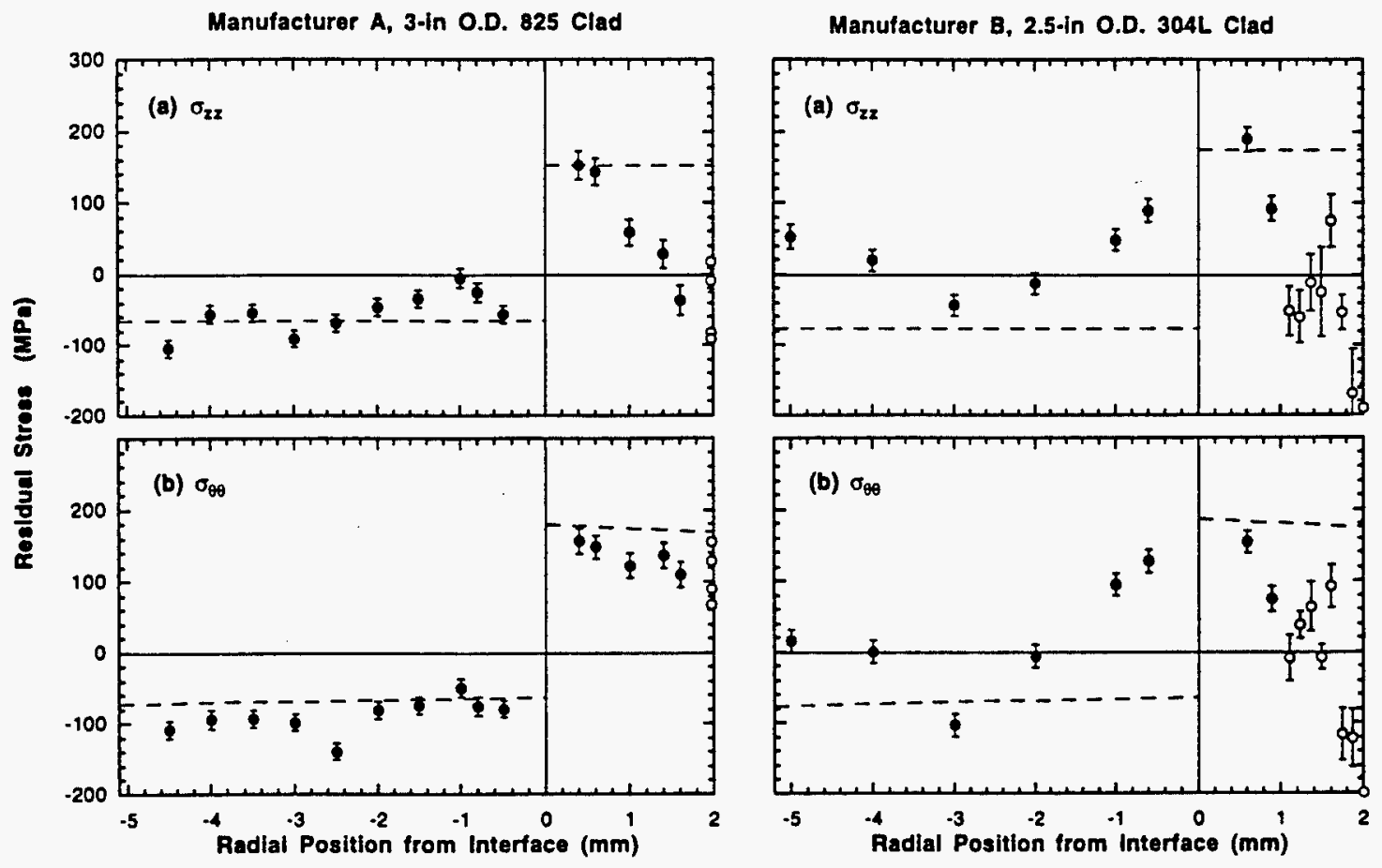

Fig. 3 Through-thickness stress profile for specimens MA 3-in 825 and MB 2.5-in $304 \mathrm{~L}$, as determined by neutron $(O)$ and $\mathrm{X}$-ray diffraction $(O)$. The $\mathrm{X}$-ray depth profiling was carried out by electro-polishing. The dashed lines are analytical calculations based on the thermal expansion mismatch between the carbon steel and the clad alloy.

A substantial difference can be seen between the calculation and experimental results. In the clad layer, for example, while the calculated residual stresses are tensile and almost constant, the experimental results show a linear decrease away from the interface and a compressive residual stress at the outer surface.

The compressive residual stress at the outer surface and the characteristic texture seen in X-ray experiments are evidence of cold-working. This could be due to the straightening or an undisclosed manufacturing process that was applied after the final heat treatment. In a recent study of residual stresses in plastically bent steel tubes, Brand et al. have shown that plastic bending introduces a strongly angular dependent residual stress state [7]. The 
non-uniform residual stresses observed in the present study (e.g., Fig. 2) are consistent with what might be expected if straightening is applied.

\section{SUMMARY}

Residual stresses in as-manufactured composite tubes were determined by means of $\mathrm{X}$-ray and neutron diffraction. The complicated manufacturing process has resulted in a complex through-thickness stress profile, which cannot be described by the thermal expansion mismatch alone. Despite the texture in the clad layer, surface residual stresses have been determined with good precision by using $\mathrm{Cr} \mathrm{K}_{\beta}$ radiation and $f c c\left(\begin{array}{lll}3 & 1 & 1\end{array}\right)$ reflection. This measurement technology combined with through-thickness neutron diffraction measurements provides a powerful means for experimental studies of residual stresses in co-extruded composite tubing.

\section{ACKNOWLEDGMENT}

The authors wish to thank S. B. Fitch, T. Johnson, and E. B. S. Pardue of TEC, Inc. for assisting the $\mathrm{X}$-ray measurements. Helpful discussions with $\mathrm{R}$. W. Swindeman and T. R. W.atkins are also gratefully acknowledged. This research was sponsored by the U. S. Department of Energy, Assistant Secretary for Energy Efficiency and Renewable Energy, Office of Industrial Technologies, Advanced Industrial Materials Program. Neutron diffraction measurements were made at the High Flux Isotope Reactor, operated with the support from U.S. Department of Energy, Office of Basic Energy Sciences. Oak Ridge National Laboratory is managed by Lockheed Martin Energy Research Corp. for the U.S. Department of Energy under contract number DE-AC05-960R22464.

\section{REFERENCES}

1. D. L. Singbeil, R. Prescott, J. R. Keiser, and R. W. Swindeman, Composite Tube Cracking in Kraft Recovery Boilers: A State-of-the-art Review, Technical Report, Oak Ridge National Laboratory, ORNL/TM-13442 (1997).

2. J. R. Keiser, B. Taljat, X.-L. Wang, P. J. Masiasz, C. R. Hubbard, R. W. Swindeman, D. L. Singbeil, and R. Prescott, "Analysis of Cracking in Coextrucded Recovery Boiler Floor Tubes," pp. 693-704 in Proc. of 1996 TAPPI Eng. Conf., TAPPI Press, Atlanta, Georgia (1996).

3. J. R. Keiser, B. Taljat, X.-L. Wang, R. W. Swindeman, P. J. Masiasz, R. L. Thomas, E. A. Payzant, D. L. Singbeil, and R. Prescott, "Analysis of Cracking in Coextrucded Recovery Boiler Floor Tubes," to appear in Proc. of 1997 TAPPI Eng. Conf.

4. X.-L. Wang, E. A. Payzant, B. Taljat, C. R. Hubbard, J. R. Keiser, and M. J. Jirinec, "Experimental Determination of the Residual Stresses in a Spiral Weld Overlay Tube," Mat. Sci. Eng., A232, $31-38$ (1997).

5. I. C. Noyan \& J. B. Cohen, p 122 in Residual Stress Measurement by Diffraction and Interpretation, Springer-Verlag, New York, USA (1987).

6. X.-L. Wang and B. Taljat, unpublished.

7. P. C. Brand, H. J. Prask, M. T. Hutchings, D. J. Buttle, and J. P. Goff, "Residual Stresses in Bent Steel Tubes Measured by Means of Neutron Diffraction and Magnetic Methods," this proceedings. 


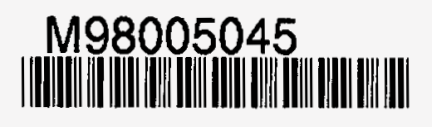

Report Number (14) $\frac{O R L / C P--96816}{C O N F-970691=}$

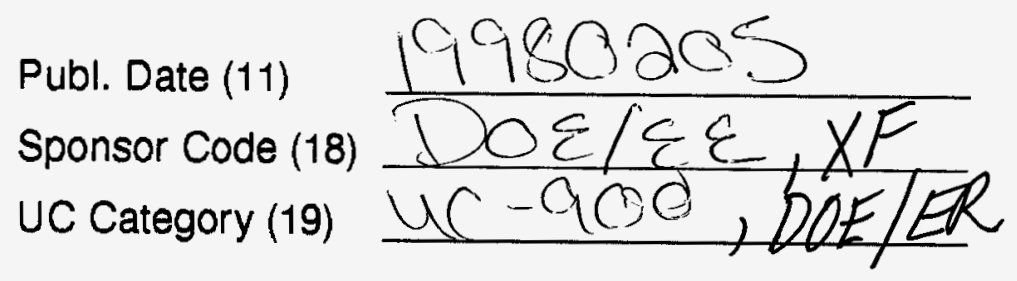

\section{3}

